\title{
Luddism, Isolation and Education
}

\section{EMMA MCKAY}

Science and Technology Studies, York University, 4700 Keele St., Toronto, ON, M3J 1P3.

emmackay@yorku.ca

\section{Responses}

JASTE is a non-refereed, open-access, journal. We encourage reader feedback on contributions to it. Please send your comments, suggestions, etc. about this paper to Emma McKay. Thanks!

\begin{abstract}
As the pandemic descended, even educators who resisted e-learning were forced to move their classes online. Undoubtedly, access to advanced communications technology has made all of this more bearable. Yet there are problems with technology. Some have more access than others, which further entrenches inequality in education. Surveillance provides only more power to the powerful. Luddism has for a long time offered a way to resist the unequal powers of technology through resisting the use of specifically those technologies which further inequality. Here, I offer a framework for Luddism that can be applied in the long term by educators and anyone else who seeks to build power in community.
\end{abstract}

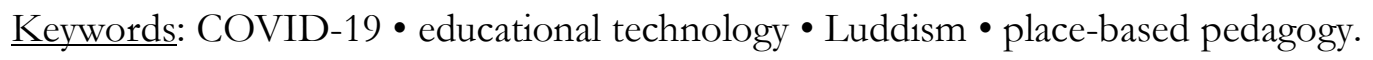

\section{Introduction}

At the end of the 18th century in Britain, technology was introduced for looms which would automate the pattern created in the textile. Many textile workers were angry, as this lowered the value of their skilled labour. They started to break the machines, and fought for decades for their right to the living they had trained for. These were the Luddites: an organized, militant movement of workers fighting against a technology of capital (Hobsbawm 1964). As our world becomes more complex, power continues to accrue in the hands of the powerful through the way this complex technology orders the world. To boot, this tech is produced through a desire to provide the military with better tools and through mining, which accounts for at least $10 \%$ of global emissions annually. Technology is, in a nutshell, problematic. NeoLuddism has evolved down many paths in response.

Today, we are all less able to see those we love, and have been reaching for technology more and more to stay connected. What do isolation and a pandemic mean for resisting technology? I hope to give something of an answer to this question here, first by exploring what Luddism is, and then by offering practical suggestions for Luddite approaches to technology in education during and after isolation. 


\section{Luddism}

There are several strains of Luddism today within and outside of academia. A review of them is outside of the scope of this article-instead, I'd like to share what I mean when I say I aspire to be a part of a Luddite society.

The Luddism I seek does not aim to destroy technology. Rather, it starts with an understanding of what technology is: a (semi-)organized system or tool which shapes the world and what people can do in it. This definition is broad and includes everything from smartphones to paper voting systems to sewing needles. Technology is not inherently good or bad because its an incredibly broad category. Rather, the effect of a piece of tech is specific to that piece-we can ask where it comes from, what it was meant for, and what relationships it changes $\&$ how. This contrasts strongly with a technocratic approach to technology, which more or less assumes that complex technology holds the answers to our problems. In dominant discourse, it is often assumed that technology is good and useful, even when it further entrenches the hegemony of colonial capitalism (Lachney 2018, King 2016).

The materials for technology themselves are sourced from the ground of this one precious planet, often without consent of the people living in the area, and at immense cost to our climate and sociobiospheres (International Resources Panel 2019). A critical approach to tech understands this origin and aims to sustain life for a long time.

Luddism calls us to make our values clear in the decisions that we make about world-shaping tools. For many neo-Luddites, those values include being anti-technocratic, anti-capitalist, and pro-long-termlivability of our planet. We can include socio-ecological considerations in big decisions-what is best for all of us everywhere we are on this planet?

Rather than think of our world as technology-centred, we can think of it as problem-centred. We have a host of central issues that we must address in this life: health \& access, food \& water, communication, shelter, managing conflict, transit, art \& entertainment, and knowledge production. We can use the value-centred nature of Luddism to judge what is most essential. In ensuring that all of these essential needs are met, we can consider our options. Some solutions will involve a great deal of complex technology; some will not. The solutions can be evaluated based on their outcomes and the resources they require, rather than how much shiny tech and new economic value they produce. A great exercise in practical Luddism is thinking about the solutions we currently employ around these issues and creatively whittling down the technology used in them or imagining what would happen if we destroyed that technology — a practice known as methodological Luddism (Lu s Garcia et al. 2018, Winner 1978).

The thing about these core issues is that they are communal. They aren't things we can change on an individual basis_your plumbing, grocery store, and workplace are mostly out of your control. I can't reject all mechanized transit if I live far from the only job I could find. I can't even readily reject having a cellphone while it's the only way that I can communicate with my family. We come back to the regular refrain: we live in a society. So, any practical change in our use of technology must be a large group e ort.

Not all of these groups have to be as big as a society (whatever that is). There are some changes which can be made within family, friend, community, and work groups to rely on different technologies. We could think, for instance, about entertainment choices for a group of friends. They might haphazardly 
each watch a Netflix series on their own over the course of several weeks, making use of the technology of on-demand streaming. Or, they could schedule a time when they can all get together every week and watch it together, making use of the technology of a calendar to reduce reliance on streaming. This is a small example, and doesn't by any means abolish the massive environmental drag that is Net ix, but we could take this as a starting point. Maybe we move forward by sharing television shows between community centres using peer-to-peer protocols over local internets and reducing our expectation that we be able to watch what we want when we want to at home.

\section{Isolation}

Now we are all alone. We can't bring the block together for a movie night (unless our building looks on to a great big white wall). How are we supposed to fill our core needs in a local \& communal way while taking their resource draw into consideration? When isolation began, I felt suddenly like all of my ideas needed to be re-evaluated. Devices and the internet were going to keep people connected, reduce tolls on mental \& physical health, and allow some to work. How could I continue to be critical of our tech-focused lives?

After dwelling in isolation for so many weeks, I feel more confirmed than ever in the Luddite approach. We clearly need to be tackling essential problems using solutions which we can, which are low resource and/or high reward for human life and all life on this planet. We've seen very clearly the important of having very good medical and public health apparatuses, for instance. This includes advanced material tech like ventilators and space in hospitals, low tech like soap and handwashing practices, and a lot of human power and associated organizational technologies and professional knowledge in nurses, doctors, and epidemiologists. A coordinated public health response involving widespread testing and contact tracing, as in South Korea, undoubtedly would have prevented thousands of deaths in Canada and maybe even isolation orders. ${ }^{1}$

Our most essential services seem to be easier to identify, even when they are missing. We need connection, supplies, and care. We feel keenly the absence of faith services, the hug of a friend, the bustle of a park. We feel confusion and outrage at the continued presence of workers building an illegal pipeline or working on condo building.

I'm also confused by the necessity of relying on internet-based communication. I wanted, before, to step away from the internet, to be more local. Now I don't talk to anyone in person. I crave the cadence of in-person chatting. It would be worse, no doubt, to be without Zoom. But we are obligated to it. Ivan Illich writes about creating tools of conviviality—spaces where our ability to choose to create together things which improve our intertwined lives (Illich 1975). It is clear that in isolation our ability to choose is more limited than before. But we also know that this is temporary, even if it lasts for a long time. We need to think of the strategic response moving forward. People's increased reliance on personal communication devices may pose an issue to convincing more of them to move away from the ubiquity of this technology.

\footnotetext{
${ }^{1}$ The Korean response has also involved a great deal of mass surveillance, which has its own problems.
} 
Many Luddite solutions to our problems are still available to us- they just still require societal buyin and long-term development. Devices can be made to be repairable, with fewer features, reducing the demand for new metals while maintaining the essential communication bene ts of a smartphone. Cities can still be made walkable and bikeable with widespread and accessible intra- and inter-city public transit. The internet can still be transformed into something which is locally connected, where people maintain local storage and rely less on streaming. It will just take time and concerted effort on the part of individuals, groups, and especially the makers of technology.

\section{Education}

Educators have been resisting technology in many ways for a long time, from early issues with adopting computers through Ontario teachers' strike demands for no required e-learning (Bryson \& De Castell 1998, Halves 2014). Stephen Lecce, the Ontario Minister of Education, said that "technological fluency is a foundational skill that also needs to be harnessed in todays disruptive economy and the trajectory of where the market is going" (Mauracher 2020). Clearly, the Ontario government, like many others, views education as basic training for the workforce and believes that the essential issue that schools must address is how to support capitalism, rather than how to improve society in a more fulsome way. Ontario teachers have resisted this requirement for several reasons. Students do not have uniform access to computers and internet. E-learning provides a poor forum for connection with students. There is also evidence that dropout rates in online courses are as high as $40 \%$, drawing deeply into question their effectiveness as a learning tool at all.

In this crisis, these core issues haven't changed all that much—we're just also in a crisis. Students don't have access to the internet, plus they and their family may have lost employment, gotten sick, or are worried about getting sick. ${ }^{2}$ Hundreds of thousands of people have already died worldwide. Many more are grieving. This Luddite approach is to identify the essential issues within this mess in line with core values and evaluate ways to address them with resources and freedoms in mind.

Core issues might include connection, support, and avoiding punishment from not meeting requirements. Perhaps continuing to meet curriculum or the planned syllabus is not a core issue. If we use a little methodological Luddism, we can imagine what parts of courses we can do without right now. Why not do this exercise with students? What do students need, and how can those needs be met with the least resource draw possible? Maybe the result will be something you all could use. Perhaps your school boards that running online classes, but maybe that doesn't require online lectures. We could try to go low-tech. Think peer-to-peer phone conversations, mail, asking for fewer assignments, going pass/fail. Let's seek what is engaging or distracting from the crises.

Most of all, responding to core issues means helping students to make sense of the change in their world and of the injustice that was already here and has manifested more intensely. The most Luddite

\footnotetext{
${ }^{2}$ We may also think about this in the terms of critical place-based pedagogy (Gruenewald/Greenwood 2003). Many of our places now are anxious, in crisis, isolated, poorer, sick, and getting sicker. How can we help students and ourselves to understand these places and to be of help to themselves and others within them? We can use a critical lens on the systems of power that have structured our world and the specific places that we are in and act locally to in response.
} 
pedagogy I can think of is one which advocates for Luddite approaches to the problems we face. Ask, with your students, what is essential? What can we go without? How can we get there together?

\section{All together now}

If we seek to build a long-lasting, livable world for all, we must be less resource-intensive, more community oriented, and drastically upend the power structures of our world. The Luddite approach discussed here is one which seeks to highlight how dependent we are on one another and on our planet, to go more slowly, and to do away with complex technology as the necessary answer to all of our problems. As educators and as individuals, the best way that we can support this is to facilitate education and community in service of local connection, community resilience, understanding the problems we face, and demanding change collectively of those with the power to enact it.

\section{References}

Bryson, M., \& De Castell, S. (1998). New technologies and the cultural ecology of primary education: Imagining teachers as Luddites in/deed. Educational Policy, 12(5), 542-567.

Gruenewald, D. (2003). The best of both worlds: A critical pedagogy of place. Educational Researcher, 32(4), 3-12.

Halves, T. (2014). Toward Luddite pedagogy. Hybrid Pedagogy. https://hybridpedagogy.org/towardluddite-pedagogy

Hobsbawm, E. (1964). Labouring Men: Studies in the History of Labour. Weidenfeld \& Nicolson.

Illich, I. (1975). Tools for conviviality. Fontana/Collins.

International Resources Panel. (2019). Global resources outlook 2019: Natural Resources for the Future We Want. https://www.resourcepanel.org/reports/global-resources-outlook

King, D. (2016). From radical science to Luddism: A post-BSSRS activist perspective on the politics of technology. Science as Culture, 25(3), 432-446.

Lachney, M., \& Dotson, T. (2018), Epistemological Luddism: Reinvigorating a concept for action in $21 \mathrm{st}$ century sociotechnical struggles. Social Epistemology, 32(4), 228-240.

Luis Garcia, J., Mateus Jeronimo, H., \& Mesquita Carvalho, T. (2018). Methodological Luddism: A concept for tying degrowth to the assessment and regulation of technologies. Journal of Cleaner Production, 197, 1647-1653.

Mauracher, J. (2020). What is e-learning and why does it have Ontario teachers concerned? Global News. https://globalnews.ca/news/6444006/e-learning-in-ontario-schools/

Winner, L. (1978). Autonomous technology: Technics-out-of-control as a theme in political thought. MIT Press. 